\title{
The Model and the Inference for the Clustered Recurrent Event
}

\author{
Kang Fang Yuan* \\ School of Applied Science, Beijing Information Science and Technology University, Beijing 100192, China
}

Submission: January 09, 2018; Published: February 28, 2018

*Corresponding author: Kang Fang Yuan, School of Applied Science, Beijing Information Science and Technology University, Beijing 100192, China, Email: fykang_003@163.com

Keywords: Tumor recurrences; Medical environment; Genetic inheritance; Asymptotic normality; Non-clustered model

Abbreviations: IPCW: Inverse Probability of Censoring Weighting; CGD: Clinic Study on Chronic Granulomatous Disease

\section{Short Communication}

In medical studies, subjects may experience one event of interest repeatedly over a period of time, which is termed recurrent event. The examples include multiple infection episodes and tumor recurrences. In many other settings, the subjects may be clustered according to some property, because they are correlated owning to some common factors. For example, medical environment and genetic inheritance have influence on the recurrence of disease. Thus, during the modeling for the recurrent event, some subjects may have dependence because of same medical facility or same family, and therefore are in the same cluster.

The recurrent event has been discussed extensively. Generally, there are two modeling methods: one is modeling for intensity function for the process [1]. The other is modeling for rate function (mean function), such as Lin et al. [2], Dai et al. [3]. The recurrent event is often precluded by a terminal event such as death. Recently, there have been several models for recurrent event with a terminal event. In many applications, however, the gap time is a natural outcome of interest [4]. Some methods have been developed for the analysis of recurrent gap time data [5-7]. For the clustered recurrent event, most of the research focuses on the marginal rate function model. Schaubel \& Cai [8] studied the marginal cox-type rate model. He et al. [9] established an additive marginal rate model. Liu et al. [10] considered a clustered recurrent event in the presence of a terminal event. However, many important models such as additive rate model, additive-multiplicative rate model and accelerated model have not been studied. Besides, there is seldom research about the clustered gap times for recurrent event.

For the clustered recurrent event in the presence of a terminal event, we developed an additive marginal rate model. Applying the estimating equation and inverse probability of censoring weighting (IPCW) technique [11], we obtained the estimator and verified the asymptotic normality. We conducted some simulating which worked well. A bladder cancer data including 117 patients was analysed (Table 1) [12,13]. For the clustered recurrent gap time, we also developed an additive hazard model. We obtained the estimator utilizing estimating equation. We simulated a clustered gap time, and then compared the clustered model and the non-clustered model. The results showed that the clustered model worked better than non-clustered model. Finally, an application to a clinic study on chronic granulomatous disease (CGD) was illustrated (Table 2).

Table 1: Estimation of the Clustered Additive Rate Model.

\begin{tabular}{|c|c|c|}
\hline Covariate & Initial Number & Treatment \\
\hline Estimate & 0.0078 & -0.0181 \\
\hline SE & 0.003 & 0.0104 \\
\hline P-value & 0.0042 & 0.0413 \\
\hline
\end{tabular}

Table 2: Estimation for CGD data under clustered model.

\begin{tabular}{|c|c|c|}
\hline Covariate & Treat & Age \\
\hline Estimate & -0.0098 & -0.0022 \\
\hline SE & 0.0022 & 0.0028 \\
\hline P-value & 0 & 0.4293 \\
\hline 95\% confidence interval & $(-0.0142,-0.0078)$ & $(-0.0054,0.0033)$ \\
\hline
\end{tabular}

\section{References}

1. Andersen PK, Gill RD (1982) Cox's regression model for counting processes: a large sample study. The Annals of Statistics. 10: 11001120.

2. Lin DY, Wei LJ, Yang L, Ying Z (2000) Semiparametric regression for the mean and rate function of recurrent events. Journal of the Royal Statistical Society, Series B. 69: 711-730.

3. Dai J J, Sun LQ Yang ZH (2009) A general additive-multiplicative rates model for recurrent event data. Science in China 52: 2257-2265. 
4. Gail MH, Santner TJ, Brown CC (1980) An analysis of comparative carcino-genesis experiments based on multiple times to tumor Biometrics. 36: 255-266.

5. Huang Y, Chen Y Q (2003) Marginal regression of gaps between recurrent events. Lifetime Data Analysis 9(3): 293-303.

6. Strawderman RL (2005) The accelerated gap times model. Biometrika 92: 1299-1315.

7. Lin DY, Sun W, Ying Z (1999) Non parametric estimation of the gap time distribution for serial events with censored data. Biometrika 86: 5970 .

8. Schaubel D, Cai J (2005) Analysis of clustered recurrent event data with application to hospitalization rates among renal failure patients. Biostatistics 6: 404-419.
9. He S, Wang F, Sun L (2013) A semiparametric additive rates model for clustered recurrent event data. Acta Mathematicae Applicatae Sinica 29(1): 55-62.

10. Liu D, Schaubel DE, Kalbfleisch JD (2012) Computationally efficient marginal models for clustered recurrent event data. Biometrics 68 : 637-647.

11. Robins J, Rotinizky A (1992) Recovery of information and adjustment for dependent censoring using surrogate markers. In AIDS Epidemiology-Methodological Issues. Birkhauser, Bosion. 297-331.

12. Park DH, Sun J (2006) The additive hazards model for recurrent gap times. Statistica Sinica 16: 919-932.

13.Zeng D, Lin D Y (2006) Efficient estimation of semiparametric transformation models with random effects for recurrent events. Biometrika 93: 627-640.

\section{Your next submission with Juniper Publishers} will reach you the below assets

- Quality Editorial service

- Swift Peer Review

- Reprints availability

- E-prints Service

- Manuscript Podcast for convenient understanding

- Global attainment for your research

- Manuscript accessibility in different formats

(Pdf, E-pub, Full Text, Audio)

- Unceasing customer service

Track the below URL for one-step submission https://juniperpublishers.com/online-submission.php 